\title{
Down-Regulation of LncRNA DGCR5 Correlates with Poor Prognosis in Hepatocellular Carcinoma
}

\author{
Ruyi Huang Xiaochen Wang Wenjie Zhang Guangyan Zhangyuan Kangpeng Jin \\ Weiwei Yu Yu Xie Xiaoliang Xu Hai Wang Beicheng Sun \\ Key Laboratory on Living Donor Liver Transplantation, Ministry of Health, Department of Liver surgery, \\ Collaborative Innovation Center For Cancer Personalized Medicine, First Affiliated Hospital of Nanjing \\ Medical University, Nanjing, P.R. China
}

\section{Key Words}

Hepatocellular carcinoma $•$ Long non-coding RNAs • DGCR5 • Cancer specific survival

\begin{abstract}
Background/Aims: Long non-coding RNAs (IncRNAs) have been reported to play pivotal roles in multiple tumors and can act as tumor biomarkers. In this study, we explored the association of the expression of an IncRNA, DGCR5 with clinicopathological features and prognosis in HCC. Methods: Expression levels of DGCR5 were detected by quantitative real-time PCR (qRTPCR) and the clinical data was obtained, including basic information, data of clinicopathology and cancer specific survival rate. Receiver operating characteristic (ROC) curve, Kaplan-Meier methods and multivariable Cox regression models were used to analyze predictive efficiency, long-term survival outcomes and risk factors. Results: DGCR5 was found down-regulated in HCC tissues $(P<0.001)$ and serum $(P=0.0035)$ and low expression of DGCR5 was correlated with a poor cancer specific survival (CSS) $(P=0.0019)$, as the overall 5-year CSS rates were 10.3\% (low expression group) and 36.6\% (high expression group), respectively. A stratified analysis demonstrated that low DGCR5 expression was an independent negative prognostic factor for HCC. In addition, the area under the ROC curve was 0.782 with a sensitivity of 0.633 and a specificity of 0.833 . Conclusions: Our results suggest that DGCR5 may be a participator in HCC and can serve as potential biomarker for the diagnosis and prognosis in HCC.
\end{abstract}

(C) 2016 The Author(s)

Published by S. Karger AG, Basel

\section{Introduction}

Liver cancer is the second most common cause of cancer-associated death worldwide, accounting for nearly 745,500 deaths in 2012 (9.1\% of the total) [1]. Hepatocellular carcinoma (HCC), which occupied $70-90 \%$ of primary liver cancer, is characterized by

R. Huang, X. Wang and W. Zhang contributed equally to this work.

Beicheng Sun and Hai Wang

KARGER
Liver Transplantation Center, The First Affiliated Hospital of Nanjing Medical University, 300 Guangzhou Road, Nanjing, Jiangsu Province 210029, (P.R. China)

Tel. +862568136746, E-Mail sunbc@njmu.edu.cn / drwanghai@126.com 


\section{Cellular Physiology Cell Physiol Biochem 2016;40:707-715 \begin{tabular}{l|l|l} 
and BOI: 10.1159/000452582 & $\begin{array}{l}\text { C } 2016 \text { The Author(s). Published by S. Karger AG, Basel } \\
\text { www.karger.com/cpb }\end{array}$
\end{tabular} \\ Huang et al.: DGCR5 Correlates with Prognosis in HCC}

invasion, metastasis and frequent recurrence after resection [2, 3]. In recent years, mounting evidences suggest that the incidence of HCC continues to increase [4], and it has been a major health problem worldwide.

Recent studies showed that HCC patients represented favorable outcomes, when diagnosed and treated at early stages [5]. However, the majority of HCC patients were diagnosed at advanced stages, which limited treatment options and prognosis [6]. One of the important reasons is that the sensitivity and specificity of the tumor marker, $\alpha$-fetoprotein (AFP) are unsatisfactory for HCC screening and diagnosis $[7,8]$. Therefore, it is an urgent task for the identification of effective biomarkers for diagnosis and prognosis in HCC.

Recently, lots of long non-coding RNAs (lncRNAs) have been reported as biomarkers for diagnosis of multiple neoplastic diseases, predicting survival and recurrence [9-11]. LncRNAs are a class of non-coding RNA which range from 200 nucleotides to multiple kilobases in length [12]. It has been widely recognized that lncRNAs play crucial roles in the regulation of multiple biological processes, including proliferation, differentiation, apoptosis, tumorigenesis and metastasis [13-17]. Moreover, there are several lncRNAs reported as biomarkers for HCC [18]. For example, previous studies showed that HULC, Linc00152 and Linc01225 were detected up-regulated significantly in tumor tissues and plasma from HCC patients and may act as novel biomarkers [19, 20]. Tang et al. [21] revealed that the combination of Linc00974 and KRT19 may be novel indices for clinical diagnosis of tumor growth and metastasis of HCC. DiGeorge syndrome critical region gene 5 (DGCR5), also known as Linc00037, is a lncRNA down-regulated in Huntington's disease neurodegeneration [22]. We found DGCR5 was deregulated in HCC when we consulted Oncomine $(P<0.05$, https://www.oncomine.org/resource/login.html), a cancer microarray database. However, few studies have been reported about the role of DGCR5 in HCC. The aim of this study is to investigate whether DGCR5 is associated with HCC and identify the role of DGCR5 in the diagnosis or prognosis in HCC.

\section{Materials and Methods}

\section{Patients and clinical samples}

Fresh HCC tissue samples and paired adjuvant non-tumor tissue samples $(n=110)$ were obtained from patients who underwent hepatic resection between 2009 and 2011 at Liver Transplantation Center of the First Affiliated Hospital, Nanjing Medical University (Nanjing, PR China). Due to the limitations that the serum samples corresponding to the HCC tissues could not be obtained, HCC serum samples $(n=60)$ were selected randomly, collected before hepatectomy. Control serum samples $(n=60)$ were selected randomly from those people undergoing physical examination. All HCC patients were confirmed by histo-pathological analysis. All samples were stored at $-80^{\circ} \mathrm{C}$ until RNA extraction and the clinical data of all patients was available. Written informed consent was obtained from all participants and the Institutional Ethics Committee of the First Affiliated Hospital, Nanjing Medical University approved the study.

RNA isolation and quantitative real-time PCR (qRT-PCR)

Total RNA was extracted from tissue samples and serum samples using TRIzol reagent (Invitrogen, Grand Island, NY, USA) as described by the manufacturer and RNAs (500 ng) were reverse transcribed using the PrimeScript RT Master Mix (Takara, Dalian, China). Quantitative real-time PCR was performed to detect the expression levels of DGCR5 using the SYBR Premix Ex Taq (Takara, Dalian, China) on the ABI Prism 7900HT (Applied Biosystems, Foster City, CA, USA). The relative expression levels of DGCR5 were normalized to GAPDH. The reactions were incubated in a 384 -well optical plate at $95^{\circ} \mathrm{C}$ for 30 seconds, followed by 40 cycles of $95^{\circ} \mathrm{C}$ for 5 seconds and $60^{\circ} \mathrm{C}$ for 30 seconds. Specific primers for GAPDH and DGCR5 were used (Table 1).

Agarose gel electrophoresis

Agarose gel electrophoresis experiments were performed using 1.0\% agarose gels with $2.5 \mu$ l Gold View (Beyotime, Nantong, China). Total RNA extracted from the serum was reverse transcribed into cDNAs and obtained cDNAs were mixed with loading buffer (Beyotime, Nantong, China). Electrophoresis was 
performed at $80 \mathrm{~V}$ for $40 \mathrm{~min}$, with $0.5 \%$ Tris-acetate-EDTA (TAE) as the running buffer. Data were analyzed with Image Lab software performed with an ultraviolet (UV) transilluminator.

Follow-up for survival

In the study, all the patients were followed-up regularly for survival analysis until death or cut-off date of study. During the follow-up period, abdominal doppler ultrasound and CT for every 3 months for 2 years. And in years 3 to 5, examinations conducted at 6 months intervals and annually thereafter.

\section{Statistical analysis}

All statistical analyses were performed using SPSS 18.0 (SPSS Inc, Chicago, IL, USA) software and presented with the GraphPad prism software (GraphPad Software, San Diego, CA, USA). Results of quantitative real-time PCR were expressed as mean \pm S.E.M. The Student's $t$ test and the Chi-square $\left(\chi^{2}\right)$ test were used to evaluate statistical differences of DGCR5 expression in different samples and e xamine the relationship between DGCR5 expression and clinicopathological features. The cancer specific survival (CSS) of patient was estimated using the Kaplan-Meier method. Analysis of area under the receiver operating characteristic (ROC) curve (AUC) was used to estimate the effectiveness of DGCR5 $\mathrm{f}$ or prediction. In all cases, $P<0.05$ was considered statistically significant.

\section{Results}

Down-regulation of DGCR5 in HCC

Compared to adjacent non-tumor tissues $(\mathrm{n}=110)$, DGCR5 was aberrantly $\mathrm{d}$ ecreased $(P<0.001)$ in tumor tissues $(\mathrm{n}=110)$, detected by qRT-PCR (Fig. 1A). Furthermore, DGCR5 expression levels in serum from patients with HCC $(n=60)$ were reduced $(P=$ $0.0035)$ in comparison with healthy controls $(n=60)($ Fig. 1B). These data reveal that DGCR5 might play a pivotal role in HCC progression.

Correlation of DGCR5 expression with clinicopathological features

In order to investigate the relationship between DGCR5 expression and clinicopathological features in HCC, the median expression level of DGCR5 in HCC tissues was used to separated the patients into low expression group $(n=65)$ and high expression group ( $\mathrm{n}=65)$ (Fig. 1C). As illustrated in Table 2, we found the DGCR5 expression was obviously associated with $\operatorname{HbsAg}(P=0.039)$ and vascular invasion $(P=0.003)$. However, other clinical factors, such as age, tumor size and histology grade, suggested no significant association with DGCR5 expression.

\section{Association of DGCR5 expression and cancer specific survival}

The 5-year liver cancer specific survival rates were $10.3 \%$ and $36.6 \%$ in low expression and high expression groups, respectively. Univariate analysis showed that larger tumor $(P=0.017)$, poor/undifferentiated grade $(P<0.001)$ and low expression of DGCR5 $(P=0.002)$ were significant risk factors for poorer prognosis. Furthermore, Edmondson grade (III-IV, HR 2.939, 95\% CI 1.757-4.916, $P<0.001$ ) and DGCR5 expression (high, HR $0.506,95 \%$ CI $0.310-0.825, P=0.006$ ) were found to be independent prognostic factors by multivariate analysis (Table 3 ).

\section{DGCR5 as a biomarker for HCC diagnosis and prognosis}

We further analyzed relationship between the expression of DGCR5 and prognosis and diagnosis by Kaplan-Meier method, log-rank test and ROC curve. The median survival periods were 33 months and 45 months in low expression and high expression groups. 
Fig. 1. Down-regulation of DGCR5 in HCC tissue and serum samples. Data was calculated by $2^{-\triangle \Delta C T}, \log$ transformed, analysed by paired $t$ test and presented as box plots. Box plot explanation: upper horizontal line of box, 75th percentile; lower horizontal line of box, 25th percentile; horizontal bar within box, median; upper horizontal bar outside box, 95th percentile; lower horizontal bar outside box, 5 th percentile. (A) relative expression level of DGCR5 in HCC tissues and the corresponding adjacent tissues. (B) relative expression level of DGCR5 in serum

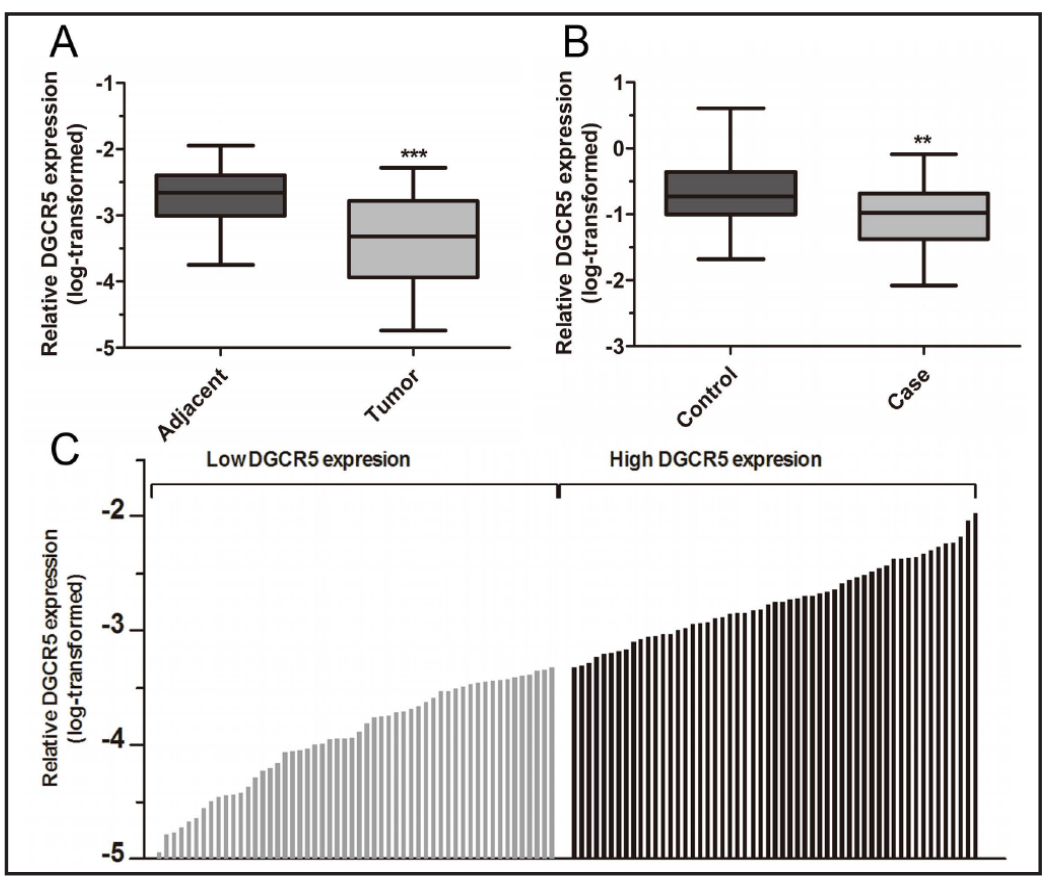
samples. (C) The HCC patients included in the study were divided into a high DGCR5 expression group and a low DGCR5 expression group according to the median value of relative DGCR5 expression in HCC tissues. Each experiment was performed in triplicate. $\left({ }^{* *} P<0.01,{ }^{* *} P<0.001\right)$.

As shown in Fig. 2A, low expression of DGCR5 was correlated with a shorter CSS $(P=0.0019)$. Our results also showed that the area under the curve (AUC) was 0.782 and DGCR5 may be an effective predictor for HCC diagnosis with a sensitivity of 0.633 and a specificity of 0.833 (Fig. 2B).

Then, we amplified DGCR5 in healthy controls and detected the amplification by agarose gel electrophoresis. Our results indicated that DGCR5 were detectable in human serum. Serum samples were frozen and thawed for five times or incubated at room temperature for $0,12,24$ and 48 hours, and expression of DGCR5 in serum detected by agarose electrophoresis and qRT-PCR indicated that DGCR5 was stably expressed in serum (Fig. 3).
Table 2. Correlation between DGCR5 expression and clinicopathological characteristics of HCC patients $(n=110)$. HBsAg: hepatitis B surface antigen. For the expression of DGCR5, median expression level in HCC tissues was used as the cutoff. Data were analyzed by chi-squared test.* indicates statistically significant

\begin{tabular}{|c|c|c|c|c|}
\hline \multirow{2}{*}{ Clinicopathological features } & \multirow{2}{*}{ Total } & \multicolumn{2}{|c|}{ DGCR5 expression } & \multirow{2}{*}{$P$ value } \\
\hline & & Low & High & \\
\hline Sex & & & & 0.751 \\
\hline Male & 99 & 50 & 49 & \\
\hline Female & 11 & 5 & 6 & \\
\hline Age & & & & 0.654 \\
\hline$\leq 60$ & 84 & 41 & 43 & \\
\hline$>60$ & 26 & 14 & 12 & \\
\hline HBsAg & & & & $0.039 *$ \\
\hline negative & 13 & 3 & 10 & \\
\hline positive & 97 & 52 & 45 & \\
\hline $\operatorname{ALT}(\mathrm{U} / \mathrm{L})$ & & & & 0.130 \\
\hline$\leq 45$ & 81 & 37 & 44 & \\
\hline$>45$ & 29 & 18 & 11 & \\
\hline AFP (ng/ml) & & & & 0.076 \\
\hline$\leq 13.6$ & 41 & 16 & 25 & \\
\hline$>13.6$ & 69 & 39 & 30 & \\
\hline Cirrhosis & & & & 0.08 \\
\hline absent & 28 & 10 & 18 & \\
\hline present & 82 & 45 & 37 & \\
\hline Vascular invasion & & & & $0.003^{*}$ \\
\hline absent & 25 & 19 & 6 & \\
\hline present & 85 & 36 & 49 & \\
\hline Tumor size $(\mathrm{cm})$ & & & & 0.067 \\
\hline$\leq 5$ & 98 & 46 & 52 & \\
\hline$>5$ & 12 & 9 & 3 & \\
\hline Edmondson grade & & & & 0.337 \\
\hline I-II & 49 & 22 & 27 & \\
\hline III-IV & 61 & 33 & 28 & \\
\hline
\end{tabular}




\section{Discussion}

Primary liver cancer is a major health problem worldwide and famous for its malignancy, with an estimated 782,500 new cases and 745,500 deaths occurred yearly [1]. $70-90 \%$ of primary liver cancer is HCC, and about $50 \%$ of the total number of cases and deaths occurred in China. In the past decade, HCC incidence is increasing because of the rising incidence in Western Europe and Northern America [6, 23, 24]. In the USA, the incidence rate of HCC increased from 2.6 per 100,000 to 8.6 per 100,000 between 1975 and 2011 [1].

In recent years, the prognosis for HCC has improved because more patients could be diagnosed at early stages and great advances had
Table 3. Univariate and multivariate survival analyses evaluating DGCR5 expressing influencing CSS in HCC. NI: not included in multivariate survival analysis. For the expression of DGCR5, median expression level in HCC tissues was used as the cutoff. All the results were adjusted using Cox proportional hazards models for tumor size, Edmondson grade and DGCR5 expression. * indicates statistically significant

\begin{tabular}{|c|c|c|c|c|c|}
\hline \multirow{2}{*}{ Variable } & \multirow[b]{2}{*}{ 5-year CSS (\%) } & \multicolumn{2}{|l|}{ Univariate analysis } & \multicolumn{2}{|c|}{ Multivariate analysis } \\
\hline & & Log rank $\chi 2$ test & $P$ & HR $(95 \% \mathrm{CI})$ & \\
\hline Sex & & 2.107 & 0.147 & & NI \\
\hline Male & $27.30 \%$ & & & & \\
\hline Female & $21.20 \%$ & & & & \\
\hline Age & & 0.074 & 0.786 & & NI \\
\hline$\leq 60$ & $25.70 \%$ & & & & \\
\hline$>60$ & $24.20 \%$ & & & & \\
\hline HbsAg & & 1.651 & 0.199 & & NI \\
\hline negative & $30.80 \%$ & & & & \\
\hline positive & $26.80 \%$ & & & & \\
\hline $\operatorname{ALT}(U / L)$ & & 0.041 & 0.839 & & NI \\
\hline$\leq 45$ & $24.70 \%$ & & & & \\
\hline$>45$ & $28.70 \%$ & & & & \\
\hline $\mathrm{AFP}(\mathrm{ng} / \mathrm{ml})$ & & 2.319 & 0.128 & & NI \\
\hline$\leq 13.6$ & $29.40 \%$ & & & & \\
\hline$>13.6$ & $20.20 \%$ & & & & \\
\hline Cirrhosis & & 0.131 & 0.717 & & NI \\
\hline absent & $25.10 \%$ & & & & \\
\hline present & $23.10 \%$ & & & & \\
\hline Vascular invasion & & 0.076 & 0.783 & & NI \\
\hline absent & $25.40 \%$ & & & & \\
\hline present & $27.60 \%$ & & & & \\
\hline Tumor size $(\mathrm{cm})$ & & 5.694 & $0.017^{*}$ & & 0.356 \\
\hline$\leq 5$ & $27.10 \%$ & & & Reference & \\
\hline$>5$ & $11.40 \%$ & & $1.408(0$ & $.681-2.911)$ & \\
\hline Edmondson grade & & 24.198 & $0.000^{*}$ & & $0.000^{*}$ \\
\hline I-II & $47.30 \%$ & & & Reference & \\
\hline III-IV & $7.20 \%$ & & $2.939(1$ & $.757-4.916)$ & \\
\hline DGCR5 expression & & 9.693 & $0.002 *$ & & $0.006^{*}$ \\
\hline low & $10.30 \%$ & & & Reference & \\
\hline high & $36.60 \%$ & & 0.5060 & $.310-0.825)$ & \\
\hline
\end{tabular}

been made in treatments for HCC, including liver resection, early-stage radiofrequency ablation and curative transplantation [25]. Clinical research has revealed that patients, treated at the early stages, had good prognosis and high overall survival rate [26, 27]. Pacella et al. [28] showed that the median overall survival duration was significantly longer in patients with main tumor size of $<2.0 \mathrm{~cm}$ (56 months, $95 \%$ CI, 46 to 66 months) versus 3.1 to $4.0 \mathrm{~cm}$ (35 months, $95 \% \mathrm{CI}, 25$ to 37 months). In a study of 8455 HCC patients, Zhang et al. [24] demonstrated that tumor size was still an important independent prognostic factor and the 36- and 60-month CSS rates dropped sharply when the tumor size reached $35 \mathrm{~mm}$. Therefore, identification of novel serum biomarkers for detecting and screening in earlystage cancer is an important goal in the diagnosis of HCC.

However, due to absence of symptoms in early phase, HCC patients were mostly diagnosed at an advanced stage still with a high mortality and a lower 5-year survival rate [6]. In addition, the main plasma tumor marker for HCC, AFP was raised in $11-58 \%$ of patients with chronic hepatitis or cirrhosis without HCC, and $30-40 \%$ of all patients with HCC were AFP negative [29, 30].

LncRNAs have been found deregulated in lots of diseases, especially in neoplastic disease [31,32], and accumulating studies have demonstrated that LncRNAs could act as tumor biomarkers $[33,34]$. H19, SNHG16, TUG1 and UCA1 were detected deregulated in bladder cancer and confirmed to be used as diagnostic markers or prognostic markers [10]. Gutschner et al. [35] demonstrated that MALAT1 was a biomarker for lung cancer metastasis and prognosis through regulating gene expression governing hallmarks of metastasis. There are several IncRNAs that have been proved to be relevant to the development and progression of HCC. Previous studies reported that Linc00974 and Linc00152 promoted 
Fig. 2. DGCR5 as a biomarker for HCC diagnosis and prognosis. (A) the median expression level in HCC tissues was used as the cutoff, and Kaplan-Meier analysis was used to discover relationship between the expression of DGCR5 and prognosis of HCC patients. (B) receiver operating characteristic curve analysis was used to evaluate the diagnosis value of DGCR5 for HCC. (C) Receiver operating characteristic curve analysis was used to evaluate the diagnosis value of DGCR5 for HCC. Area under the curve (AUC) was 0.769 with a sensitivity of 0.683 and a specificity of 0.8 .

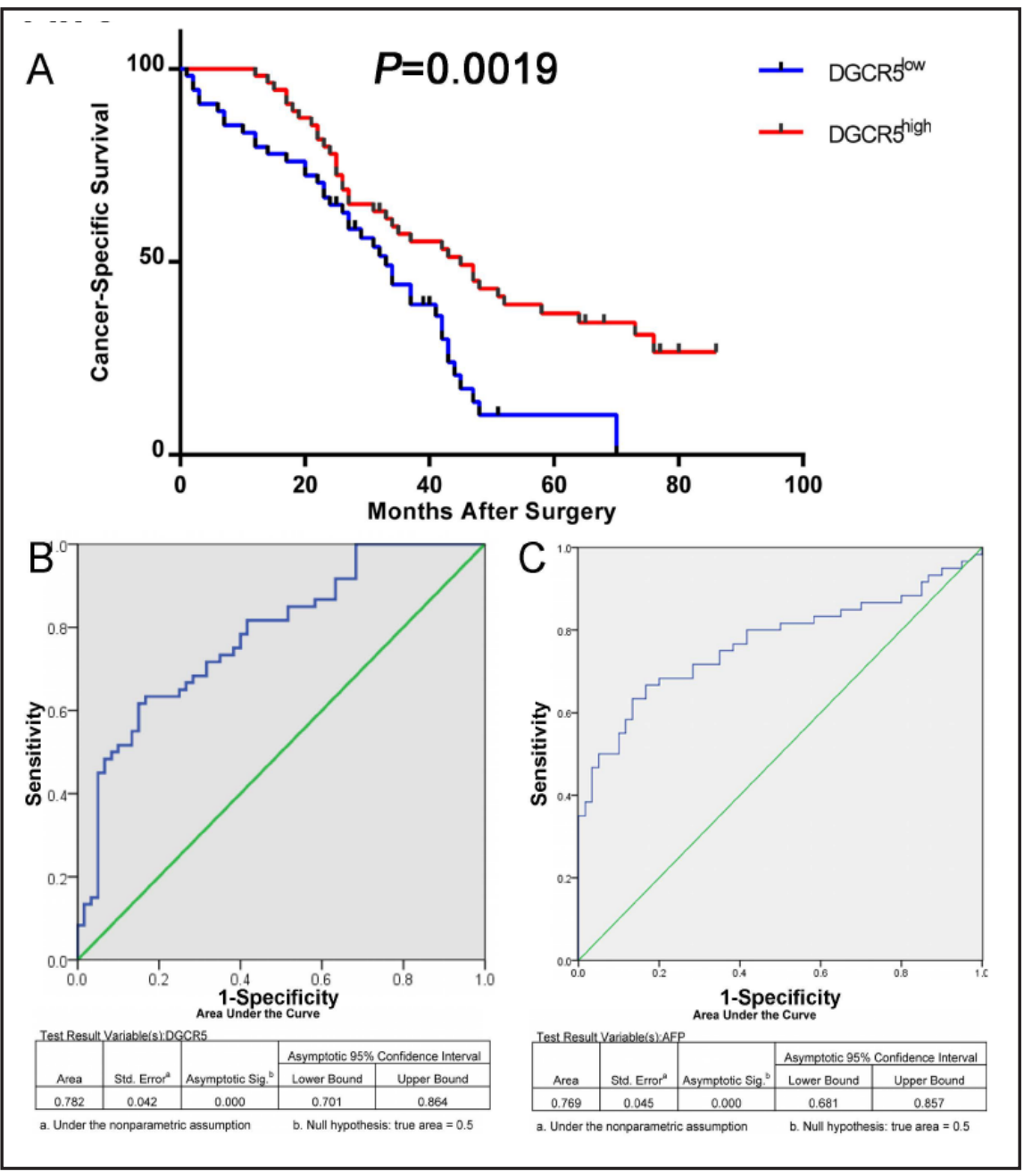

Fig. 3. The stability of DGCR5 in human serum. The products of the amplification fragment of DGCR5 in serum were detected by agarose electrophoresis. (A and B) Serum samples were frozen and thawed for five times, and expression of DGCR5 detected by agarose electrophoresis and qRT-PCR. (C and D) Serum samples were incubated at room temperature for $0,12,24$ and 48 hours, and expression of DGCR5

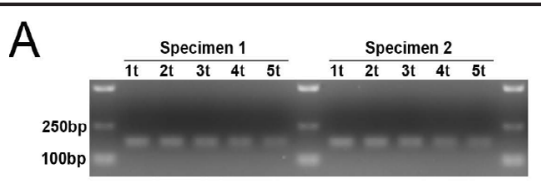

B

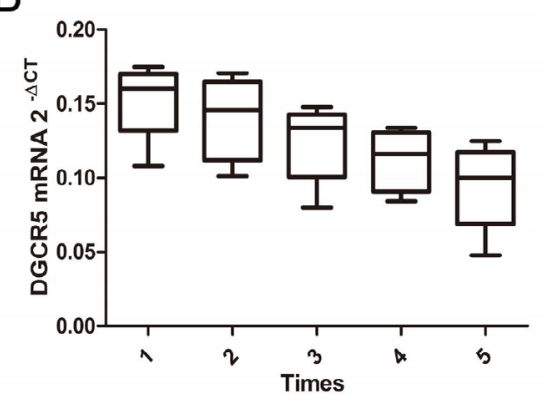

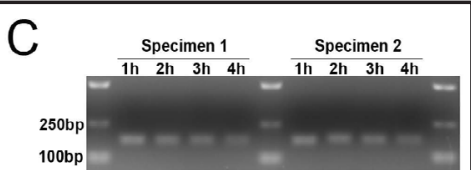

$\mathrm{D}$

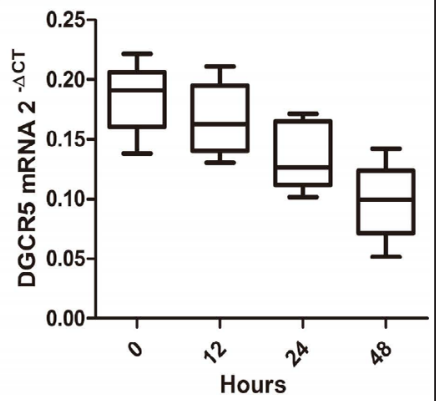

detected by agarose electrophoresis and qRT-PCR. The " $\mathrm{t}$ " and " $\mathrm{h}$ " are representative of times and hours, respectively. Each experiment was performed in triplicate.

proliferation in HCC by targeting EpCAM and KRT19 [21, 36]. Wang et al. [19] demonstrated that Linc01225 promoted occurrence and metastasis of HCC in an epidermal growth factor 


\section{Cellular Physiology Cell Physiol Biochem 2016;40:707-715 \begin{tabular}{ll|l} 
DOI: 10.1159/000452582 & $\begin{array}{l}\text { O 2016 The Author(s). Published by S. Karger AG, Basel } \\
\text { www.karger.com/cpb }\end{array}$ \\
\hline
\end{tabular} \\ Huang et al.: DGCR5 Correlates with Prognosis in HCC}

receptor-dependent pathway. DGCR5 is a human non-coding RNA located at chromosome 22q11 with 3334 bp (http://www.ncbi.nlm.nih.gov/gene/26220). However, the role of DGCR5 in the clinicopathology and prognosis in HCC has not been reported.

In the present study, we found that DGCR5 was significantly down-regulated in HCC tissues compared with that in adjacent non-tumor tissues, which was consistent with the Oncomine database $(P<0.05)$. More important, we found that the median survivals were 33 months and 45 months in low expression and high expression group, respectively. Low expression of DGCR5 was significantly associated with a shorter CSS, which suggested that DGCR5 has important functions in the progression of HCC. All above study revealed that DGCR5 may be a promising biomarker for the prognosis in HCC. Thus, we detected serum DGCR5 expressing and found that DGCR5 expressing was significantly down-regulated in serum from patients with HCC than in that from healthy controls. Therefore, DGCR5 may serve as potential biomarker for predicting the diagnosis in HCC. To confirm this, ROC curve analysis was used and the result showed the evidence for great value of DGCR5. The area under the ROC curve of DGCR5 (0.782), with a sensitivity of 0.633 and a specificity of 0.833 , is similar to that of AFP (0.769) with a sensitivity of 0.683 and a specificity of 0.8 (Fig. 2C).

Univariate analysis showed that patient with large tumor, poorly or undifferentiated grade and low DGCR5 expression had a poor 5-year CSS. As pivotal factors, the associations of tumor size and differentiated grade with survival had been analyzed widely in HCC. Takayasu et al. [37] demonstrated that the prognosis of patients with HCC was associated with tumor size in a cohort of 8,510 patients. In a study included 788 patients, Nathan et al. [38] showed that pathologic staging was still an important independent prognostic factor. Similar results were also reported by Zhang and his colleagues [24]. In this study, we identified median value of DGCR5 in HCC tissues as the cutoff to divide patients into two subgroups. The 5-year CSS rates were $10.3 \%$ and $36.6 \%$ in the low DGCR5 group and high DGCR5 group, respectively, and low DGCR5 expression was a risk factor for poor survival. Further stratified analysis demonstrated that Edmondson grade and DGCR5 expression were validated as independent prognostic factors of survival in multivariate Cox regression.

In summary, our study revealed DGCR5 expression was down-regulated in HCC patients and can serve as a potential biomarker for the diagnosis and prognosis in HCC. However, the molecular mechanisms of DGCR5 that involved in HCC need to be further studied.

\section{Acknowledgements}

This work was supported by grants from the National Natural Science Foundation for Distinguished Young Scholars (Grant no. 81225017 to B.S.), the State Key Program of National Natural Science of China (Grant no. 81430062 to B.S.), the National Key Research and Development Program of China (Grant no. 2016YFC0905900 to B.S.). This work was also supported in part by the Priority Academic Program of Jiangsu Higher Education Institutions. B.S. is Yangtze River scholars Distinguished Professor.

\section{Disclosure Statement}

The authors declared no conflict of interest.

\section{References}

1 Torre LA, Bray F, Siegel RL, Ferlay J, Lortet-Tieulent J, Jemal A: Global cancer statistics, 2012. CA Cancer J Clin 2015;65:87-108.

2 Venook AP, Papandreou C, Furuse J, de Guevara LL: The incidence and epidemiology of hepatocellular carcinoma: A global and regional perspective. Oncologist 2010;15:5-13. 


\section{Cellular Physiology Cell Physiol Biochem 2016;40:707-715

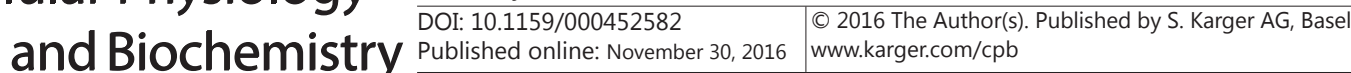 \\ Huang et al.: DGCR5 Correlates with Prognosis in HCC}

3 Sahasrabuddhe VV, Gunja MZ, Graubard BI, Trabert B, Schwartz LM, Park Y, Hollenbeck AR, Freedman ND, McGlynn KA: Nonsteroidal anti-inflammatory drug use, chronic liver disease, and hepatocellular carcinoma. J Natl Cancer Inst 2012;104:1808-1814.

4 Fitzmorris P, Shoreibah M, Anand BS, Singal AK: Management of hepatocellular carcinoma. J Cancer Res Clin Oncol 2015;141:861-876.

5 Midorikawa Y, Takayama T, Shimada K, Nakayama H, Higaki T, Moriguchi M, Nara S, Tsuji S, Tanaka M: Marginal survival benefit in the treatment of early hepatocellular carcinoma. J Hepatol 2013;58:306-311.

6 Llovet JM, Burroughs A, Bruix J: Hepatocellular carcinoma. Lancet 2003;362:1907-1917.

7 Marrero JA, Romano PR, Nikolaeva O, Steel L, Mehta A, Fimmel CJ, Comunale MA, D'Amelio A, Lok AS, Block TM: Gp73, a resident golgi glycoprotein, is a novel serum marker for hepatocellular carcinoma. J Hepatol 2005;43:1007-1012.

8 Giannini EG, Marenco S, Borgonovo G, Savarino V, Farinati F, Del Poggio P, Rapaccini GL, Anna Di Nolfo M, Benvegnù L, Zoli M, Borzio F, Caturelli E, Chiaramonte M, Trevisani F: Alpha-fetoprotein has no prognostic role in small hepatocellular carcinoma identified during surveillance in compensated cirrhosis. Hepatology 2012;56:1371-1379.

9 Vencken SF, Greene CM, McKiernan PJ: Non-coding rna as lung disease biomarkers. Thorax 2015;70:501503.

10 Martens-Uzunova ES, Böttcher R, Croce CM, Jenster G, Visakorpi T, Calin GA: Long noncoding rna in prostate, bladder, and kidney cancer. Eur Urol 2014;65:1140-1151

11 Yang ZT, Li Z, Wang XG, Tan T, Yi F, Zhu H, Zhao JP, Zhou XF: Overexpression of long non-coding rna zxf2 promotes lung adenocarcinoma progression through c-myc pathway. Cell Physiol Biochem 2015;35:23602370.

12 Wahlestedt C: Targeting long non-coding rna to therapeutically upregulate gene expression. Nat Rev Drug Discov 2013;12:433-446.

13 Piao HL, Ma L: Non-coding rnas as regulators of mammary development and breast cancer. J Mammary Gland Biol Neoplasia 2012;17:33-42.

14 Tang J, Jiang R, Deng L, Zhang X, Wang K, Sun B: Circulation long non-coding rnas act as biomarkers for predicting tumorigenesis and metastasis in hepatocellular carcinoma. Oncotarget 2015;6:4505-4515.

15 Yin DD, Zhang EB, You LH, Wang N, Wang LT, Jin FY, Zhu YN, Cao LH, Yuan QX, De W, Tang W: Downregulation of lncrna tug1 affects apoptosis and insulin secretion in mouse pancreatic beta cells. Cell Physiol Biochem 2015;35:1892-1904.

16 Luo G, Wang M, Wu X, Tao D, Xiao X, Wang L, Min F, Zeng F, Jiang G: Long non-coding rna meg3 inhibits cell proliferation and induces apoptosis in prostate cancer. Cell Physiol Biochem 2015;37:2209-2220.

17 Chen J, Lin C, Yong W, Ye Y, Huang Z: Calycosin and genistein induce apoptosis by inactivation of hotair/pakt signaling pathway in human breast cancer mcf-7 cells. Cell Physiol Biochem 2015;35:722-728.

18 Li C, Chen J, Zhang K, Feng B, Wang R, Chen L: Progress and prospects of long noncoding rnas (lncrnas) in hepatocellular carcinoma. Cell Physiol Biochem 2015;36:423-434.

19 Wang X, Zhang W, Tang J, Huang R, Li J, Xu D, Xie Y, Jiang R, Deng L, Zhang X, Chai Y, Qin X, Sun B: Linc01225 promotes occurrence and metastasis of hepatocellular carcinoma in an epidermal growth factor receptordependent pathway. Cell Death Dis 2016;7:e2130.

20 Li J, Wang X, Tang J, Jiang R, Zhang W, Ji J, Sun B: Hulc and linc00152 act as novel biomarkers in predicting diagnosis of hepatocellular carcinoma. Cell Physiol Biochem 2015;37:687-696.

21 Tang J, Zhuo H, Zhang X, Jiang R, Ji J, Deng L, Qian X, Zhang F, Sun B: A novel biomarker linc00974 interacting with krt19 promotes proliferation and metastasis in hepatocellular carcinoma. Cell Death Dis 2014;5:e1549.

22 Johnson R: Long non-coding rnas in huntington's disease neurodegeneration. Neurobiol Dis 2012;46:245254.

23 Zhang W, Sun B: Impact of age on the survival of patients with liver cancer: An analysis of 27,255 patients in the seer database. Oncotarget 2015;6:633-641.

24 Zhang W, Wang X, Jiang R, Hou J, Mu X, Li G, Sun B: Effect of tumor size on cancer-specific survival in small hepatocellular carcinoma. Mayo Clin Proc 2015;90:1187-1195.

25 El-Serag HB, Marrero JA, Rudolph L, Reddy KR: Diagnosis and treatment of hepatocellular carcinoma. Gastroenterology 2008;134:1752-1763. 


\section{Cellular Physiology Cell Physiol Biochem 2016;40:707-715 \begin{tabular}{ll|l} 
DOI: 10.1159/000452582 & $\begin{array}{l}\text { O 2016 The Author(s). Published by S. Karger AG, Basel } \\
\text { wwww.karger.com/cpb }\end{array}$
\end{tabular} \\ Huang et al.: DGCR5 Correlates with Prognosis in HCC}

26 Cucchetti A, Piscaglia F, Cescon M, Colecchia A, Ercolani G, Bolondi L, Pinna AD: Cost-effectiveness of hepatic resection versus percutaneous radiofrequency ablation for early hepatocellular carcinoma. J Hepatol 2013;59:300-307.

27 Altekruse SF, McGlynn KA, Dickie LA, Kleiner DE: Hepatocellular carcinoma confirmation, treatment, and survival in surveillance, epidemiology, and end results registries, 1992-2008. Hepatology 2012;55:476482.

28 Pacella CM, Francica G, Di Lascio FM, Arienti V, Antico E, Caspani B, Magnolfi F, Megna AS, Pretolani S, Regine R, Sponza M, Stasi R: Long-term outcome of cirrhotic patients with early hepatocellular carcinoma treated with ultrasound-guided percutaneous laser ablation: A retrospective analysis. J Clin Oncol 2009;27:2615-2621.

29 Farinati F, Marino D, De Giorgio M, Baldan A, Cantarini M, Cursaro C, Rapaccini G, Del Poggio P, Di Nolfo MA, Benvegnu L, Zoli M, Borzio F, Bernardi M, Trevisani F: Diagnostic and prognostic role of alpha-fetoprotein in hepatocellular carcinoma: Both or neither? Am J Gastroenterol 2006;101:524-532.

30 Johnson PJ: The role of serum alpha-fetoprotein estimation in the diagnosis and management of hepatocellular carcinoma. Clin Liver Dis 2001;5:145-159.

31 Yang L, Lin C, Jin C, Yang JC, Tanasa B, Li W, Merkurjev D, Ohgi KA, Meng D, Zhang J, Evans CP, Rosenfeld MG: Lncrna-dependent mechanisms of androgen-receptor-regulated gene activation programs. Nature 2013;500:598-602.

32 Zhou X, Ye F, Yin C, Zhuang Y, Yue G, Zhang G: The interaction between mir-141 and lncrna-h19 in regulating cell proliferation and migration in gastric cancer. Cell Physiol Biochem 2015;36:1440-1452.

33 Wang Y, Gao S, Liu G, Jia R, Fan D, Feng X: Microarray expression profile analysis of long non-coding rnas in human gastric cardiac adenocarcinoma. Cell Physiol Biochem 2014;33:1225-1238.

34 Tang Q, Ni Z, Cheng Z, Xu J, Yu H, Yin P: Three circulating long non-coding rnas act as biomarkers for predicting nsclc. Cell Physiol Biochem 2015;37:1002-1009.

35 Gutschner T, Hämmerle M, Eissmann M, Hsu J, Kim Y, Hung G, Revenko A, Arun G, Stentrup M, Gross M, Zörnig M, MacLeod AR, Spector DL, Diederichs S: The noncoding rna malat1 is a critical regulator of the metastasis phenotype of lung cancer cells. Cancer Res 2013;73:1180-1189.

36 Ji J, Tang J, Deng L, Xie Y, Jiang R, Li G, Sun B: Linc00152 promotes proliferation in hepatocellular carcinoma by targeting epcam via the mtor signaling pathway. Oncotarget 2015;6:42813-42824.

37 Takayasu K, Arii S, Ikai I, Omata M, Okita K, Ichida T, Matsuyama Y, Nakanuma Y, Kojiro M, Makuuchi M, Yamaoka Y: Prospective cohort study of transarterial chemoembolization for unresectable hepatocellular carcinoma in 8510 patients. Gastroenterology 2006;131:461-469.

38 Nathan H, Schulick RD, Choti MA, Pawlik TM: Predictors of survival after resection of early hepatocellular carcinoma. Ann Surg 2009;249:799-805. 